\title{
Comparison study of nucleation and growth characteristics of chemical-vapor-deposited diamond films on $\mathrm{CoSi}_{2}(001)$ and $\mathrm{Si}(001)$
}

\author{
C. Z. Gual and X. Jiang ${ }^{\mathrm{b})}$ \\ Fraunhofer-Institut für Schicht- und Oberflächentechnik, Bienroder Weg 54E, 38108 Braunschweig, \\ Germany \\ L. Kappius and S. Mantl \\ Institut für Schicht- und lonentechnik, Forschungszentrum Jülich GmbH, 52425 Jülich, Germany
}

(Received 8 September 1999; accepted for publication 29 October 1999)

\begin{abstract}
Epitaxial $\mathrm{CoSi}_{2}$ (001) layers, deposited on $\mathrm{Si}(001)$ substrates by molecular beam allotaxy, were used as substrates for diamond deposition in order to realize applications. The nucleation and textured growth of diamond films were compared with those on the $\mathrm{Si}(001)$ substrates. The results indicate that in a microwave-plasma chamber diamond can be nucleated with a higher density on $\mathrm{CoSi}_{2}$ at lower temperatures using a bias-enhanced method. High-quality [001]-textured diamond films can be synthesized on $\mathrm{CoSi}_{2}$ (001) using the [001]-textured growth conditions. So far, epitaxial growth of diamond on $\mathrm{CoSi}_{2}$ cannot be observed. Statistically, a rotating angle distribution of diamond grains around the [001] axis in a [001]-textured film shows, however, preferred in-plane orientations of $13^{\circ}, 22^{\circ}, 45^{\circ}$, and $77^{\circ}$ relative to the $\mathrm{CoSi}_{2}[011]$ axis. The structural and chemical analyses show that no $\mathrm{Co}$ and $\mathrm{Si}$ element diffusion from the $\mathrm{CoSi}_{2}$ substrate into the diamond film can be detected. The films grown on $\mathrm{CoSi}_{2}$ have similar crystal quality to that of epitaxial films deposited directly on Si. (C) 2000 American Institute of Physics. [S0021-8979(00)10203-8]
\end{abstract}

\section{INTRODUCTION}

Metal silicides are one of the most promising materials for microelectronics because of their low resistivity and high thermal stability and it is possible for them to be grown epitaxially on $\mathrm{Si}$ substrates. ${ }^{1,2}$ The resistivity of $\mathrm{CoSi}_{2}$, with a cubic $\mathrm{CaF}_{2}$ structure, is less than $20 \mu \Omega \mathrm{cm}$ and the lattice mismatch to $\mathrm{Si}$ is $1.2 \%$. $\mathrm{CoSi}_{2}$ has been used as a contact material between the metallization layer and devices in complementary metal-oxide-semiconductor-integrated circuits. Both thermal and electrical stabilities are improved by reducing the parasitic resistance at the shallow junction, and resistivity values can also be lowered. ${ }^{3} \mathrm{CoSi}_{2}$ can also be used as an interconnect conductor in semiconductor devices and is an active material for developing nanometer dimension devices.

Chemical-vapor-deposited (CVD) diamond films present excellent mechanical, optical, thermal, electrical, and chemical properties and are interesting for numerous industrial applications. ${ }^{4}$ It has been used as tool coatings, heat sinks, high-temperature semiconductor materials, etc. Particularly oriented or textured CVD diamond films are more efficient in realizing the above applications. However, some problems remain unresolved, such as the poor adhesion of diamond with metal substrates for cutting tools and insufficient Ohmic contact with the metallization layer in heat sinks as well as in electronics device applications. 5,6 The poor film adhesion is often caused by catalytic reactions between the gas species

\footnotetext{
a) On leave from the National Laboratory of Superhard Materials, Jilin University, Changchun 130023 P. R. China.

b) Author to whom correspondence should be addressed; electronic mail: jiang@ist.fhg.de
}

for diamond growth and the elements contained in substrates (Fe, $\mathrm{Co}$, and $\mathrm{Ni}$ ) forming carbon soot. $\mathrm{CoSi}_{2}$ may be a good candidate as a barrier layer between the diamond film and substrate materials to prevent the diffusion of such elements from the substrate and to increase the adhesion of the diamond films. Diamond, as an active electronic and sensor material, is considered to be used in harsh conditions (high temperature, corrosive environment). A thermally stable $\mathrm{CoSi}_{2}$ as the contact material can decrease the contact resistance and prolong the lifetime of the devices, especially as an interconnection conductor.

Few papers relating to CVD diamond growth on silicides include the nucleation and growth kinetics of diamond on $\mathrm{FeSi}_{2}$ and $\mathrm{CoSi}_{2}$. Singh and Vellaikal reported that an interlayer of $\mathrm{FeSi}_{2}$ on $\mathrm{Si}$ (100) enhanced the diamond nucleation density by more than an order of magnitude. ${ }^{7}$ Arnault, Lang, and Normand observed a large delay for the diamond nucleation process on $\mathrm{CoSi}_{2}$ in a hot-filament CVD (longer induction time in comparison to silicon). ${ }^{8}$

In this article, the nucleation and growth of diamond films on epitaxial $\mathrm{CoSi}_{2}$ layers were investigated. The $\mathrm{CoSi}_{2}$ layers were deposited by a molecular beam allotaxy (MBA) on $\mathrm{Si}(001)$. Bias-enhanced nucleation (BEN) and [001]textured growth were performed in a microwave plasma process. The nucleation and textured growth characteristics on $\mathrm{CoSi}_{2}$ are compared with those on $\mathrm{Si}(001)$.

\section{EXPERIMENT}

A $2 \mu \mathrm{m}$ epitaxial $\mathrm{CoSi}_{2}$ layer was grown on a $4 \mathrm{in}$. mirror-polished $n$-type $\mathrm{Si}(001)$ wafer by the MBA process. ${ }^{9,10}$ During this process, the simultaneous epitaxial growth of the matrix and the formation of precipitates with a 
TABLE I. Deposition parameters of the specimens.

\begin{tabular}{lll}
\hline \hline \multicolumn{1}{c}{ Step } & Nucleation & Growth \\
\hline $\mathrm{CH}_{4}$ flow rate $(\mathrm{sccm})$ & 15 & 12.5 \\
$\mathrm{CO}_{2}$ flow rate $(\mathrm{sccm})$ & 0 & 2.5 \\
$\mathrm{H}_{2}$ flow rate $(\mathrm{sccm})$ & 285 & 285 \\
Microwave power $(\mathrm{W})$ & 800 & 1200 \\
Substrate temperature $\left({ }^{\circ} \mathrm{C}\right)$ & $600-1000$ & 720 \\
Pressure (mbar) & 20 & 40 \\
Bias voltage $(\mathrm{V})$ & -150 & 0 \\
\hline \hline
\end{tabular}

peaked concentration profile were important characteristics of allotaxial growth. High-temperature annealing promotes precipitate coarsening and coalescence, finally leading to planar layer formation. The structure and composition of $\mathrm{CoSi}_{2}$ on $\mathrm{Si}$ were confirmed by Rutherford backscattering spectrometry (RBS) and cross-sectional transmission electron microscopy (TEM). The experimental details have been described in Ref. 9.

An ASTeX microwave-plasma chemical-vapor deposition (MWCVD) reactor equipped with a $3 \mathrm{~kW}$ generator and a bias system was used for diamond nucleation and growth on $\mathrm{CoSi}_{2}$ and $\mathrm{Si}$. A well-established two-step process (biasenhanced nucleation and textured growth), which was described in our previous work for deposition of [001]-oriented diamond film on $\mathrm{Si}(001),{ }^{11}$ was used. For a direct comparison of nucleation behaviors of diamond on $\mathrm{CoSi}_{2}$ with those obtained on $\mathrm{Si}$ substrate, the diamond films were deposited simultaneously on the $\mathrm{CoSi}_{2}$ layer and on the mirrorpolished $\mathrm{Si}(001)$ wafer. The experimental details are given in Table I.

The morphology and crystallographic orientation or texture of the diamond films on $\mathrm{CoSi}_{2}$ and $\mathrm{Si}$ were evaluated by scanning electron microscopy (SEM). Micro-Raman spectroscopy was used to obtain information about the phase purity of the films. To further confirm the growth characteristics of films on $\mathrm{CoSi}_{2}$, electron probe microanalysis (EPMA) was performed to analyze the structures and compositions of the substrate materials and diamond films. The existence of cobalt and silicon elements in the diamond film on $\mathrm{CoSi}_{2}$ was investigated by RBS. The He-ion energy was $1.4 \mathrm{MeV}$ and the scattering angle was $170^{\circ}$.

\section{RESULTS AND DISCUSSION}

\section{A. Nucleation}

[001]-oriented diamond nuclei on $\mathrm{Si}(001)$ substrates can be acquired with a two-step method, our previous work has reported the nucleation step was usually carried out at a substrate temperature around $850{ }^{\circ} \mathrm{C} .{ }^{11}$ Figure 1 shows the nucleation densities on $\mathrm{Si}$ and $\mathrm{CoSi}_{2}$ under various substrate temperatures. At $850^{\circ} \mathrm{C}$, the nucleation density on $\mathrm{Si}$ is $10^{10} \mathrm{~cm}^{-2}$. This density magnitude is suitable to further grow completed film in the short time of about $30 \mathrm{~min}$. The nucleation density on a $\mathrm{CoSi}_{2}$ substrate at $850^{\circ} \mathrm{C}$ is only about $10^{8} \mathrm{~cm}^{-2}$. At higher nucleation temperatures $\left(900^{\circ} \mathrm{C}\right)$, the density on the Si substrate did not clearly change, and the density for $\mathrm{CoSi}_{2}$ substrate decreases drastically. If the nucleation was performed at $780^{\circ} \mathrm{C}$, the density of the nuclei

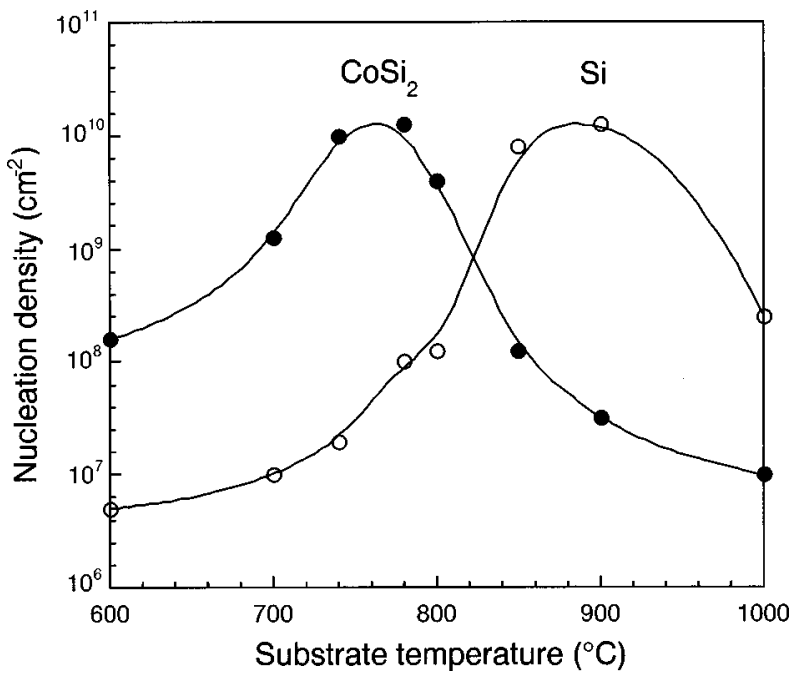

FIG. 1. Nucleation density of diamond films deposited on $\mathrm{CoSi}_{2}$ and $\mathrm{Si}$ substrates as functions of the substrate temperature.

on $\mathrm{Si}$ decreases to $10^{8} \mathrm{~cm}^{-2}$, and that for $\mathrm{CoSi}_{2}$ increases to $10^{10} \mathrm{~cm}^{-2}$, which reaches the same level as on $\mathrm{Si}$ at $850^{\circ} \mathrm{C}$.

The mechanisms of enhanced nucleation of diamond on $\mathrm{Si}$ or $\mathrm{CoSi}_{2}$ during the CVD process under a substrate bias voltage are not very clear, although bombardment of ions with an energy of $\sim 100 \mathrm{eV}$ was confirmed to be a key condition. $^{12}$ The attraction of positively charged energetic ions due to the negative bias increases the bombardment of the substrate surface, which has two effects: Creation of surface defects of the substrate, which will serve as active nucleation sites, and enhancement of the surface diffusion of adatoms. ${ }^{13} \mathrm{CoSi}_{2}$, being a lower resistance material compared to the $n$-type $\mathrm{Si}(100)$ used in our experiments (Si resistivity: $3-9 \Omega \mathrm{cm}$ ), has a more strong attraction to positively charged ions under the negative bias. The bias potential can, therefore, be more effectively applied to the substrate, which results in higher nucleation density at lower temperature. The maximum nucleation rates observed for both $\mathrm{Si}$ and $\mathrm{CoSi}_{2}$ substrates can be explained by the opposing effects of the desorption of hydrogen from the silicon surface and the sticking probability of carbon species and etching of the diamond phase. The shift of the density maximum to a lower temperature for $\mathrm{CoSi}_{2}$ may be interpreted as the result of the increased effectivity of biasing the substrate-both nucleation and hydrogen etching occur at lower temperature due to the higher substrate conductivity of $\mathrm{CoSi}_{2}$ in comparison to $\mathrm{Si}$.

\section{B. Oriented growth on $\mathrm{Si}$ and $\mathrm{CoSi}_{2}$}

To further analyze the crystallographic orientation of the diamond nuclei on $\mathrm{Si}$ and $\mathrm{CoSi}_{2}$, the textured growth process was performed for $2 \mathrm{~h}$ after 20 min nucleation at $850^{\circ} \mathrm{C}$. Figures 2(a) and 2(b) show the surface morphologies of diamond films deposited on $\mathrm{Si}$ and $\mathrm{CoSi}_{2}$. A closed film can be deposited on Si and a large portion of grains are [001] oriented. Some misoriented grains still exist. The grain size was relatively small (about $0.7-1 \mu \mathrm{m}$ ) on Si because of its higher nucleation density. Figure 2(b) represents isolated twinned 


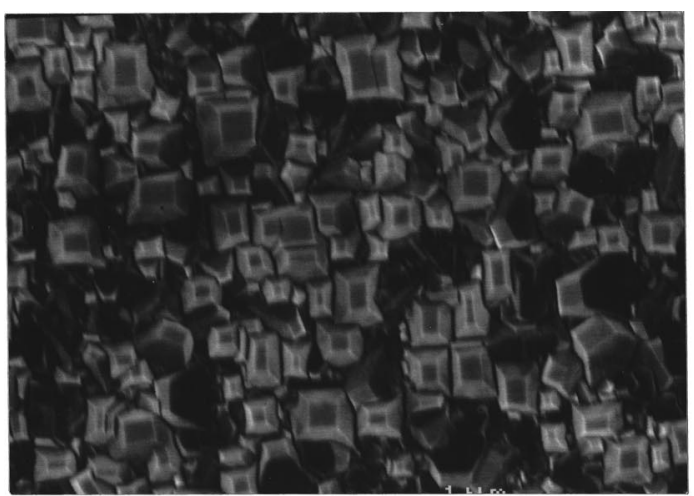

(a) $-1 \mu \mathrm{m}$

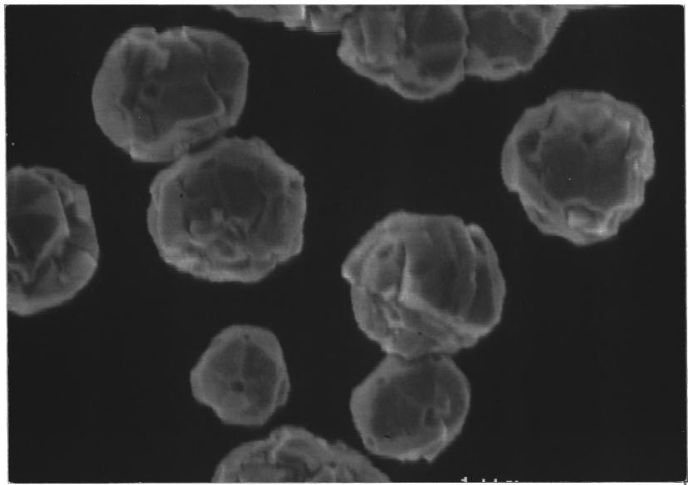

(b)

$1 \mu \mathrm{m}$

FIG. 2. SEM images of diamond grains on (a) $\mathrm{Si}$ and (b) $\mathrm{CoSi}_{2}$ at $850{ }^{\circ} \mathrm{C}$.

diamond crystallites grown on $\mathrm{CoSi}_{2}$ with a larger grain size (about 1.5-2 $\mu \mathrm{m}$ ) because of its lower nucleation density. A completed film could not be grown with this sample.

At a lower temperature of $780^{\circ} \mathrm{C}$, the experiment was performed otherwise under the same conditions. The surface morphologies of the prepared film samples on $\mathrm{Si}$ and $\mathrm{CoSi}_{2}$ are shown in Figs. 3(a) and 3(b). [001]-oriented grains can still be formed on $\mathrm{Si}$, but the grain size is larger (about 1.5-2 $\mu \mathrm{m})$ than that shown in Fig. 2(a). This is obviously also due to the lower nucleation density at low temperature (Fig. 1). Figure 3(b) shows a completed film with relatively small grain size (about $0.5-1 \mu \mathrm{m}$ ) on $\mathrm{CoSi}_{2}$. The amount of twinned diamond crystallites has been clearly reduced and [001]-oriented grains become dominant.

If a longer deposition process is performed, the films become more closed and the orientation degree increases due to the evolutional selection process. Figure 4(a) shows a 5 - $\mu$ m-thick film on $\mathrm{Si}$ after $15 \mathrm{~h}$ growth. An epitaxially [001]-oriented film was obtained. In contrast, only a [001]textured film with similar grain size was obtained on $\mathrm{CoSi}_{2}$ [Fig. 4(b)]. By careful inspection of the grain orientation, one can find an in-plane preferential distribution of grain orientations. The rotating angle distribution of diamond [110] grain axis in Fig. 5 shows a dominant maximum at $45^{\circ}$ relative to the [110] axis of the underlying $\mathrm{CoSi}_{2}$ layer, indicating an orientation relationship $[100]_{\text {diamond }} \|[011]_{\mathrm{CoSi}_{2}}$. Other preferential directions can also be found at $13^{\circ}, 22^{\circ}$,

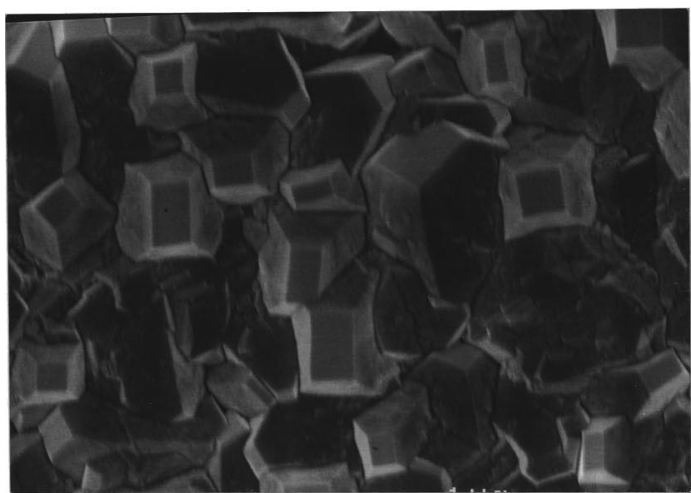

(a) $=1 \mu \mathrm{m}$

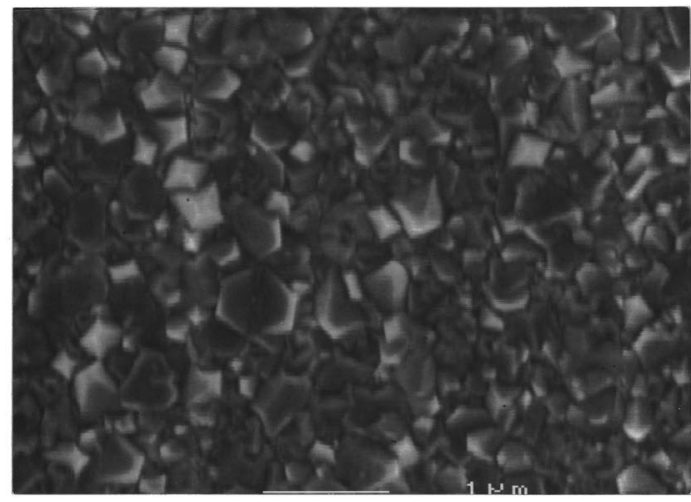

(b)

\section{$1 \mu \mathrm{m}$}

FIG. 3. SEM images of diamond grains on (a) $\mathrm{Si}$ and (b) $\mathrm{CoSi}_{2}$ at $780{ }^{\circ} \mathrm{C}$.

and $77^{\circ}$ among which the maxima at $13^{\circ}$ and $77^{\circ}$ are symmetric to the $45^{\circ}$ axis.

A special $\mathrm{Si}$ substrate, which was partially covered by the $\mathrm{CoSi}_{2}$ layer, was used to further verify the growth characteristics of the diamond films on $\mathrm{Si}$ and $\mathrm{CoSi}_{2}$. On this sample, exactly the same nucleation and growth conditions can be realized. Figure 6 shows the film morphology. As is expected, a film with areas of different orientation perfections can be distinguished-a heteroepitaxial [001] film area (left side) and a area of [001]-textured film with a random in-plane orientation (right side). On the different areas, EPMA was employed to analyze the interface between the diamond film and the substrate (Fig. 7). It is shown that there is no Co element at the interface between the epitaxial film and substrate, indicating direct growth of the film on the $\mathrm{Si}(001)$ surface [Fig. 7(a)]. On the [001]-textured film area, the Co element was found at the interface between the film and substrate, indicating the film deposition on the $\mathrm{CoSi}_{2}$ (001) layer.

Even though the lattice mismatch of $\mathrm{CoSi}_{2}$ is $-1.2 \%$ relative to $\mathrm{Si}$ at room temperature, the diamond growth presents different characteristics on $\mathrm{Si}$ and $\mathrm{CoSi}_{2}$. The reason is still unclear. One may attribute these results to the different crystal structures, chemical bondings at the interface, and effects of deposition parameters for the above two kinds of substrates. It has been reported that a Si-rich carbide layer may be formed between diamond and $\mathrm{CoSi}_{2}{ }^{14}$ this will 


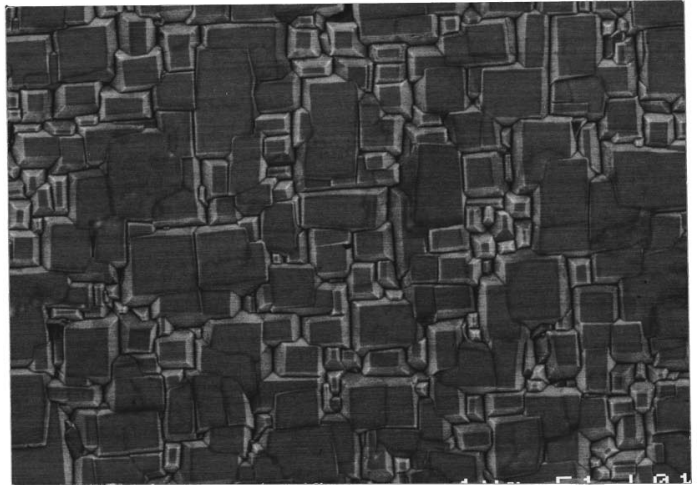

(a)

$2 \mu \mathrm{m}$

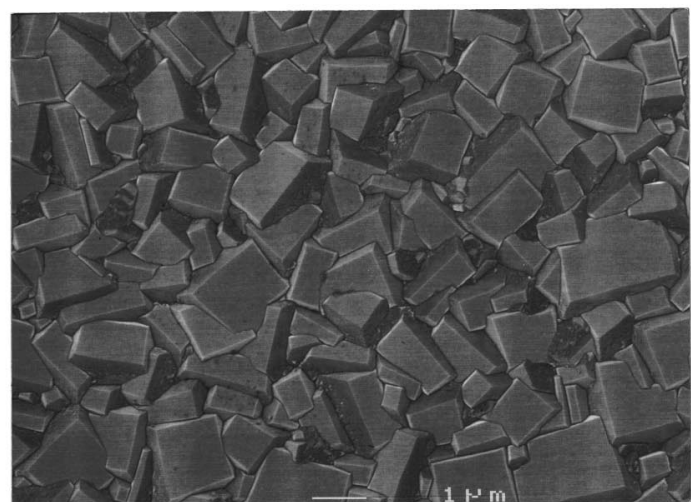

(b)

$2 \mu \mathrm{m}$

FIG. 4. SEM images of diamond films on (a) $\mathrm{Si}$ and (b) $\mathrm{CoSi}_{2}$ under the same growth conditions.

change the lattice constant of the substrate surface.

To obtain information about the phase purity, microRaman spectroscopy was performed on the diamond films deposited on $\mathrm{CoSi}_{2}$ and $\mathrm{Si}$ in a same deposition process. The Raman spectra shown in Fig. 8 present similar characteristics. The first-order diamond line at $1333 \mathrm{~cm}^{-1}$ and a very low broad signal at wave numbers from 1400 to $1600 \mathrm{~cm}^{-1}$

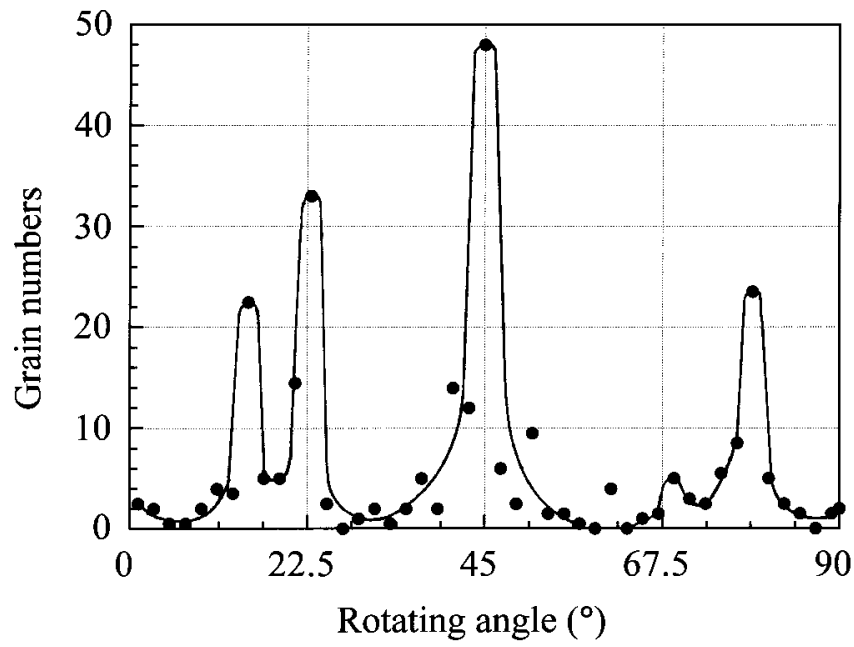

FIG. 5. Rotating angle distribution of diamond grains in a [001]-textured film deposited on $\mathrm{CoSi}_{2}$ relative to the [011] axis of $\mathrm{CoSi}_{2}$.

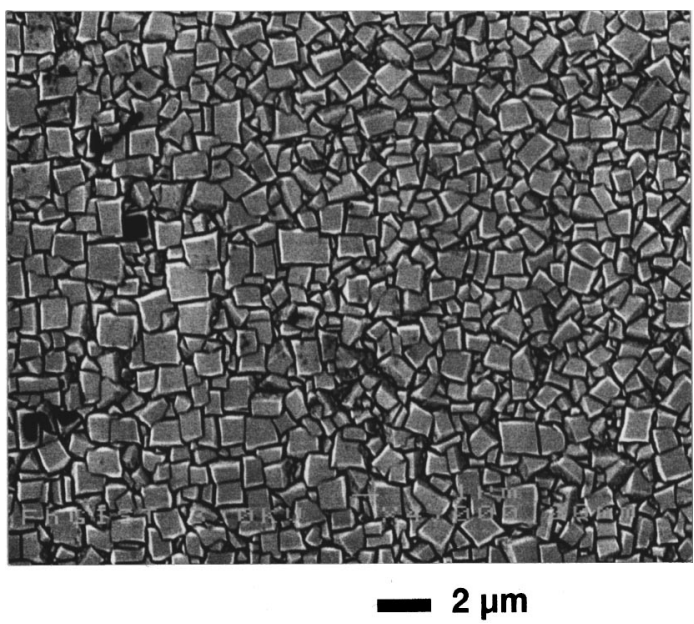

FIG. 6. SEM image of a diamond film on a special Si substrate, the surface of which was partially covered by the $\mathrm{CoSi}_{2}$ layer.

were detected. The broad feature results from phase impurities, such as tetrahedrally bonded amorphous carbon and graphite. From Fig. 8 it is obvious that high-quality diamond films can be obtained on both $\mathrm{CoSi}_{2}$ and $\mathrm{Si}$ substrates.

It is well known that CVD diamond films can be used as tool coatings to significantly prolong the lifetime of $\mathrm{WC}-\mathrm{Co}$ cutting tools used in machining materials free from ferrous metals. It is well recognized, however, that the Co contained in the binder phase of the hard metal is detrimental to the
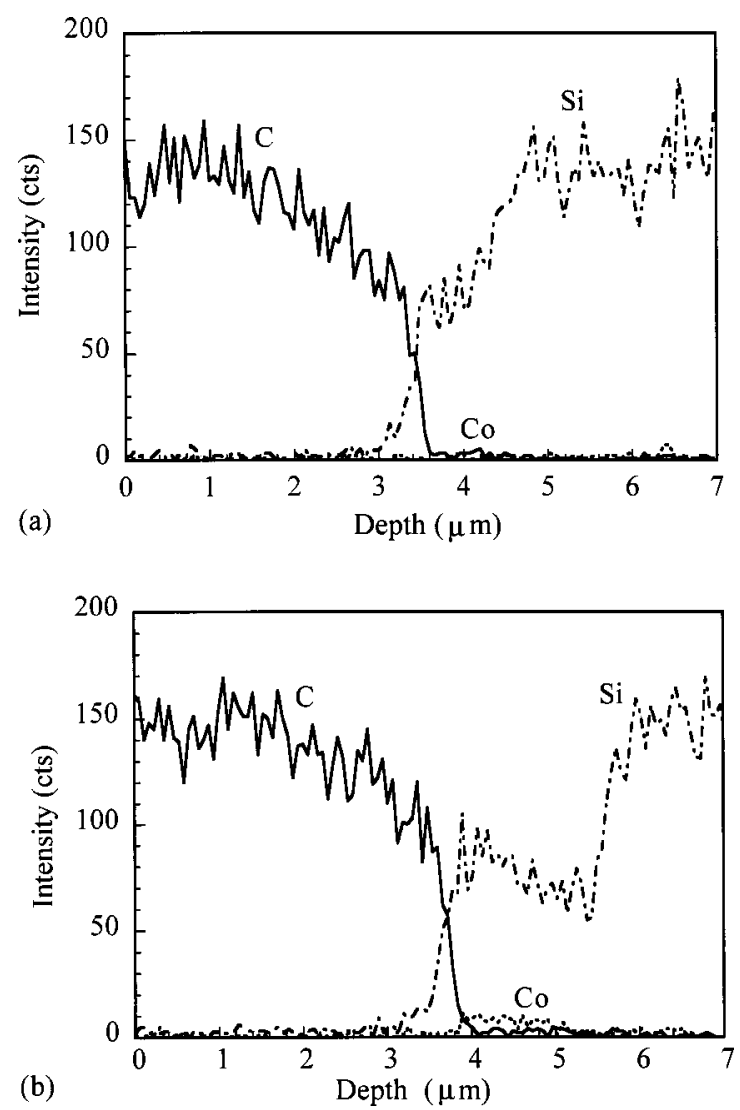

FIG. 7. EPMA depth profiles obtained by scanning cross sections of a diamond/Si sample (a) and of a diamond/CoSi ${ }_{2} / \mathrm{Si}$ sample (b). 


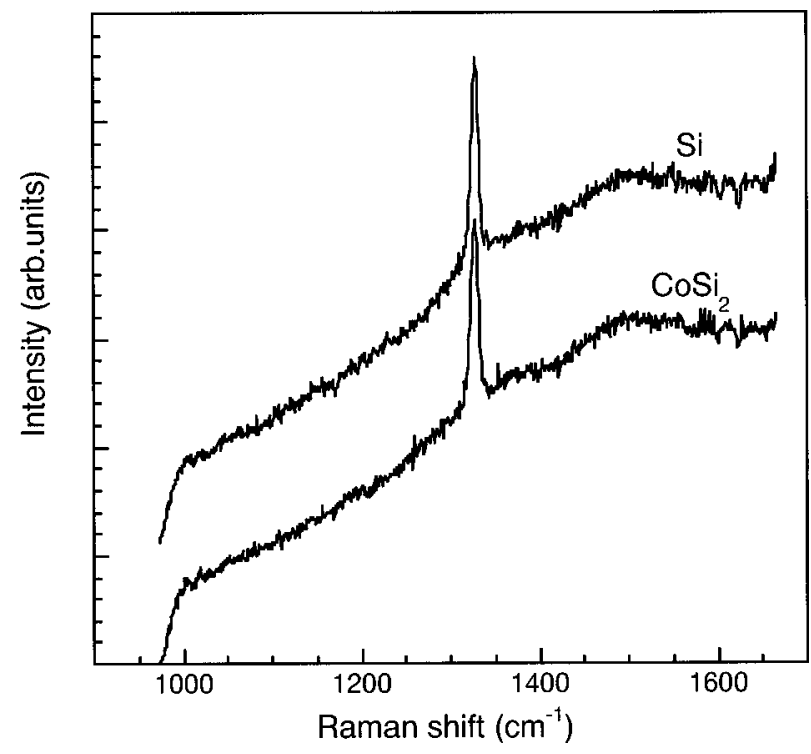

FIG. 8. Raman spectra obtained from diamond film deposited on $\mathrm{Si}$ and $\mathrm{CoSi}_{2}$.

growth of CVD diamond. Enriched Co on the surface of WC-Co will react with the carbon-containing species forming graphite and, therefore, prevent the nucleation of diamond and inhibit the very strong adhesion between the diamond coating and the hard metal substrate required for all cutting tool applications. Our experiments have shown that high nucleation density, high-quality, and [001]-textured diamond films can be deposited on $\mathrm{CoSi}_{2}$ without any indication of such a catalytic reaction. To further prove that $\mathrm{CoSi}_{2}$ can be used as a barrier layer for diamond deposition on hard metals, RBS was employed to analyze $\mathrm{Co}, \mathrm{Si}$, and other elements in the diamond films deposited on $\mathrm{CoSi}_{2}$. The result is shown in Fig. 9. No $\mathrm{Si}$ and Co peaks can be detected in the RBS spectrum. This result confirms that neither Co nor $\mathrm{Si}$ diffuse from the substrate into the diamond film at our experimental conditions, and therefore, $\mathrm{CoSi}_{2}$ can be considered as a stable barrier layer between the diamond film and hard metal substrate, which hinders the diffusion of other elements from the substrate and decreases their negative effects on adhesion.

\section{CONCLUSION}

Diamond films have been nucleated and grown on $\mathrm{CoSi}_{2}$ using a microwave-plasma CVD method. The nucleation and textured growth characteristics of the diamond film on $\mathrm{CoSi}_{2}$ were compared with those on $\mathrm{Si}$. The results indicate that using bias-enhanced nucleation, high-density diamond crystallites can be nucleated on $\mathrm{CoSi}_{2}$ at a relatively low sub-

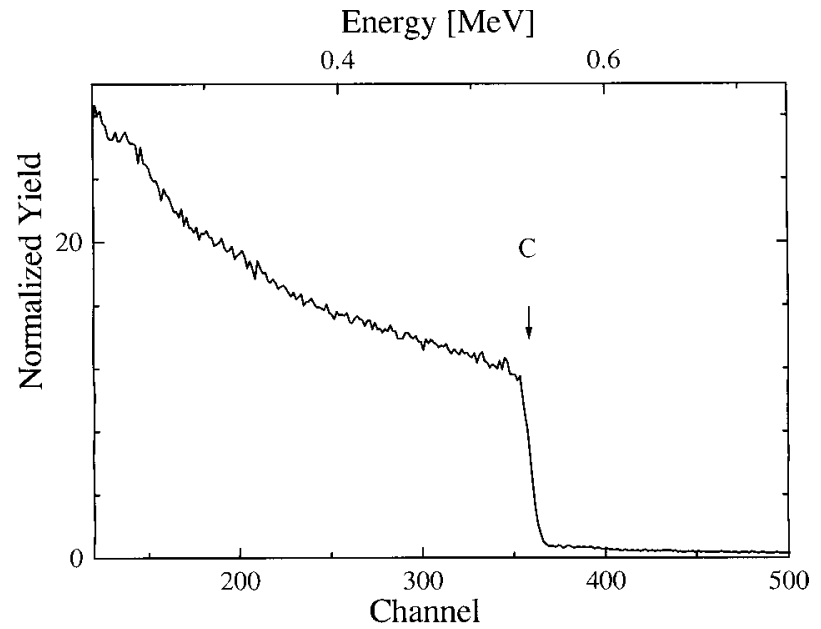

FIG. 9. RBS spectrum obtained from a diamond film deposited on $\mathrm{CoSi}_{2}$. The He-ion energy was $1.4 \mathrm{MeV}$ and the backscattering angle was $170^{\circ}$. The sample was tilted by $5^{\circ}$. The energy of the carbon surface signal is indicated.

strate temperature. High-quality [001]-textured diamond films can be synthesized onto $\mathrm{CoSi}_{2}$ using the same growth conditions as on $\mathrm{Si}$ substrates. In relation to [001]-textured films deposited on $\mathrm{CoSi}_{2}$, the statistical rotating angle measurement of grains indicates preferential distributions at $13^{\circ}$, $22^{\circ}, 45^{\circ}$, and $77^{\circ}$ relative to the [011] axis. SEM, EPMA, and Raman analyses confirm similar growth characteristics of films on $\mathrm{CoSi}_{2}$ as directly grown on silicon. RBS measurements show no Co and Si diffusion from the substrate to the diamond films deposited on $\mathrm{CoSi}_{2}$, indicating that $\mathrm{CoSi}_{2}$ can be a good stable barrier layer and interlayer for special mechanical and electronic applications.

${ }^{1}$ J. S. Byun, D. K. Kim, W. S. Kim, and H. J. Kim, J. Appl. Phys. 78, 1725 (1995)

${ }^{2}$ T. I. Selinder, D. J. Miller, and K. E. Gray, Appl. Phys. Lett. 67, 1597 (1995).

${ }^{3}$ M. L. A. Dass, D. B. Fraser, and C. S. Wei, Appl. Phys. Lett. 58, 1308 (1991).

${ }^{4}$ K. E. Spear, J. Am. Ceram. Soc. 72, 171 (1989).

${ }^{5}$ T. H. Huang, C. T. Kuo, C. S. Chang, C. T. Kao, and H. Y. Wen, Diamond Relat. Mater. 1, 594 (1992).

${ }^{6}$ W. D. Brown, H. A. Naseem, A. P. Malshe, J. H. Glezen, and W. D. Hinshaw, Proceedings of the Proc. Spring Materials'95, San Francisco, CA, 1995, MRS, p. 180.

${ }^{7}$ J. Singh and M. Vellaikal, Surf. Coat. Technol. 64, 131 (1994).

${ }^{8}$ J. C. Arnault, B. Lang, and F. L. Normand, J. Vac. Sci. Technol. A 16, 494 (1998).

${ }^{9}$ S. Mantl and H. L. Bay, Appl. Phys. Lett. 61, 267 (1992).

${ }^{10}$ S. Mantl, J. Phys. D 31, 1 (1998).

${ }^{11}$ X. Jiang and C-P. Klages, Diamond Relat. Mater. 2, 1112 (1993).

${ }^{12}$ J. Robertson, J. Gerber, S. Sattel, M. Weiler, K. Jung, and H. Ehrhardt, Appl. Phys. Lett. 66, 3287 (1995).

${ }^{13}$ X. Jiang, W. J. Zhang, and C.-P. Klages, Phys. Rev. B 58, 7064 (1998).

${ }^{14}$ S. Kubelka, R. Haubner, B. Lux, R. Steiner, G. Stingeder, and M. Grasserbauer, Diamond Relat. Mater. 3, 1360 (1994). 